processes have created entirely new branches of overseas trade. At home, improved containers have been installed on the railways, and more compact and efficient freezing plant has been evolved. As a result the consumer has been able to receive quicker deliveries, fresher food and greater variety. A vivid impression was conveyed to the audience of the different problems which have already been solved by showing them lantern slides iliustrating the imposing provision made on board ship and on rail for the transport of such commodities as meat, bananas, etc.

\section{Social Implications}

That topics concerning nutrition and malnutrition are still liable to be controversial issues was apparent with the opening of the general discussion by the president of the Association, Sir Josiah Stamp, who pleaded for scientific definition of the terms used andstatistical treatment of conclusions, and emphasized that these questions have social and even political implications. How, he asked, can one define the "amount of money needed for an optimum diet" when a French housewife is able to manage on so much less than her English counterpart, or how is one to define the "amount of money available for food" when it depends on how much of it is spent on beer !

\section{Food Science and Agriculture}

Prof. H. G. Denham, who followed, spoke of the benefits which scientific research has rendered to agriculture in New Zealand, and Prof. W. J. Young, of Melbourne, paid a similar tribute on behalf of Australia. In New Zealand the use of superphosphate has enabled the farmer to put a cow on every acre instead of only one cow on three or four acres. As a result of the drop in its price, the consumption of butter has been greatly increased. In the same way, the consumption of milk might be raised with marked effects for good on many sections of the community. Another contribution of the chemist to agriculture and to food science is the discovery that borax cures a disease of Cox's orange apples. Another is that cobalt, not iron, is needed to secure New Zealand sheep against certain common infectious diseases. Both Prof. Denham and Prof. Young united in expressing their obligation to the work of the Low Temperature Research Station at Cambridge.

The value and indispensability of the contribu. tion of the analytical chemist to food science was the theme chosen by Dr. G. Roche Lynch, president of the Society of Public Analysts and other Analy. tical Chemists. As he pointed out, much of our "newer knowledge of nutrition" has its origin in the work of the public analyst in controlling the adulteration of food.

\title{
Positive Economics of the Fungi
}

$\mathrm{T}$ $\mathrm{HE}$ emphasis of the study of economic mycology is so much upon the negative side, the effect of fungi as producers of disease, that it is very stimulating to have the presidential address to Section K (Botany) of the British Association, delivered on September 10, deal with the beneficial activities of these organisms. Mr. J. Ramsbottom has collected very numerous examples where fungi are of positive value to the community, and his paper makes fascinating reading.

Perhaps the most obvious use of fungi is as articles of food. In addition to the common mushroom, blewits (Tricholoma personatum) and species of the genus Boletus (B. edulis and B. scaber) are eaten in Great Britain; but Mr. Ramsbottom also mentioned the use of Pholiota agerita and Polyporus tuberaster, of literary lore, the Canadian Grifolia (Polyporus) Tuckahoe, the Indian bread of America (Poria cocos), the blackfellow's bread of Australia (Polyporus mylittce) and various tropical species of the genus Lentinus. Three species of the larger fungi are cultivated by man, namely, the field mushroom, the shiitake (Cortinellus Shiitake) and Volvaria volvacea. A historical review of the development of mushroom culture finds a natural place in Mr. Ramsbottom's puper, and a consideration of modern methods of pure. culture also appears therein. Production of the shiitake has little horticultural similarity to mushroom growing. A pile of logs is sprinkled with powdered wood from previously infected material, or covered with straw mats bearing spores. The cultivation of Volvaria volvacea is less precise, for heaps of rice straw, chopped banana leaves, or other vegetable refuse, are merely watered with rice-wash or sugar-cane juice, and usually bear within a fortnight. There is an extensive cultivation of this fungus within the tropics.

Truffles (Tuber spp.) still occur in Great Britain, and Mr. Ramsbottom's paper contains an implicit invitation for field mycologists to follow the example of C. E. Broome, who, in the middle of last century, always used a rake upon his fungus forays, and found truffles from very numerous localities. 
A whimsical reference to the criminal use of poisonous fungi led to a consideration of the medicinal value of certain species. Lycoperdon Bovista has been used in the past for stanching wounds, ergot of rye (Claviceps purpurea) holds the seal of the British Pharmacopœia, and many other examples of more homely uses of fungal remedies are given. Cordyceps sinensis, a parasite of caterpiliars, is much used in China, being sold along with the caterpillar, and tied with red silk.

Perhaps few dentists or fly fishermen would recognize the soft flesh of Fomes fomentarius as the amadou of their craft, and relatively few photographers have experienced the use of the inky juice of Coprinus comatus as a retouching medium. Hottentot and Egyptian ladies used fungus spores as face powder, and one wonders why their modern sisters have not made greater use of the delicate shades of spore colour for this purpose. Wood attacked by fungi is not necessarily worthless. The green colour of oak or birch attacked by Chlorosplenium aruginosum is the 'green wood' used in the manufacture of Tunbridge ware, whilst 'brown oak' of commerce is the result of inoculation with Fistulina hepatica. A most fascinating use of a mould, Mucor racemosus, is described from Chiloe Island and eastern Patagonia, for there the wood of such trees as Eucryphia cordifolia, Weinmannia trichosperma and species of Nothofagus, is converted to a palatable food for cattle by the agency of the fungus and associated bacteria.

No account of the uses of fungi would be complete without some reference to the symbiotic mycorrhiza of orchid plants. The work of Noel Bernard showed that inoculation with a fungus was necessary for the germination of orchid seeds, and gave abundant growth where previously had been great waste of seed. Although the work of B. L. Knudson has shown that the seed can germinate under aseptic conditions, if supplied directly with glucose, the symbiotic method of Bernard is still used extensively in some countries.

A very large part of Mr. Ramsbottom's address dealt, very naturally, with fermentative changes brought about by fungi. As an introduction to this section, he quoted the discovery of nineteen different enzymes-_"apparently sufficient for any purpose here below"-from the fungus Aspergillus Oryza. Compressed yeast, which is now used extensively in bread manufacture, has evolved gradually from the older preparations, as leavens, barms and more liquid ferments. Wines are still made chiefly with naturally occurring yeasts, usually allied to Saccharomyces ellipsoideus; but various strains of $S$. cerevisice are maintained in pure culture for all the more distinctive brands of beer. A point of general mycological interest is the discovery by K. Kruis and J. Satava that there is an alternation of generations in yeasts; Torula and other non-sporing forms are regarded as haploid phases.

The world's coal resources must come to an end sooner or later, and it is very satisfying to have the assurance that suitable methods for the production of power alcohol could be brought into operation on a large scale, as soon as international interest should demand. Fungal organisms can also be employed for the conversion of starch to sugar in malting operations, and give better results than the use of enzymes derived from the germinating grain.

Mr. Ramsbottom had many interesting facts to relate about the production of fermented foods and drinks. The reader cannot but revel in the international nature of his discourse, for he described the preparation of shoyu koji, from soy beans in Japan, China, Java and other countries, tamari, miso, to-fu, from the same parts, sake, a beverage made from rice in Japan, and the ripening of various kinds of cheese in all parts of the world, and probably dating back to Neolithic times. There is also detailed mention of Russian kvass, Mexican pulque, laette in Scandinavia, the old English ginger-beer plant, kephir and koumiss, beverages made from fermented milk in central Asia, leben, a similar drink of Egypt, and mazu of the Armenians. The accounts of cheese-ripening are particularly interesting, and many practical problems are described. One cannot but sympathize, for example, with the up-to-date farmer who pulled down his old wooden dairy shelves, and replaced them with tile and slate, only to find that he had also parted with the "esteemed special quality" of his Stilton cheeses-the wooden shelves had been the unsuspected culture medium for the specific organism concerned.

The work originated by Pasteur led to a new era in the production of organic compounds, and since the time when Van Tieghem, Pasteur's pupil, first studied the formation of gallic acid from tannin, many compounds have been produced mycologically. Glycerol, which is a very important compound in many industries, can be produced if sugar is fermented in the presence of alkaline salts. W. Connstein and K. Ludecke, under the stress of war conditions in 1914, showed that disodium sulphite was much more suitable than the commoner alkaline salts; it could be added in large quantities without detriment to the yeast, and kept out other contaminating organisms. Commercial diastase, oxalic and citric acids, gluconic acid, and an imposing host of organic compounds, some of them never previously prepared in the laboratory, have been made by the action of fungi. Exhaustion of our coal reserves 
need have no terrors, for in addition to power alcohol, dyestuffs can be made with the aid of fungal organisms. $\quad \alpha$-Hydroxyanthroquinone pigments can be produced through the agency of certain species of the genus Helminthosporium. Ergosterol, fats and proteins must also be added to the list of mycologically producible substances, and the discovery by Chapman that a species of Oidium, found to be blocking sewer channels, could produce a thick film on nutrient medium, which had the odour and flavour of cream cheese, illustrates the romantic possibilities of science.

There is a great deal in Mr. Ramsbottom's address which can be used to render the acquirement of knowledge by the student a pleasant experience. The subject-matter is about candy, cheese, 'Marmite', coffee, mushrooms, baking and brewing-instances of common experience; but the discourse gave sufficient detail to make it of interest to the technician also. The dominant impression was one of confidence in the future. Natural mineral resources are now being exploited at an enormous rate, to produce power, dyestuffs and various chemicals; but many of these needs could also be met by the gentle ministrations of fungi. Perhaps the large number of substances already produced by these organisms might be taken as earnest that man need not fear the exhaustion of Nature's experiment with carboniferous conservation.

\section{Genetics and Ecology in Relation to Selection}

$\mathrm{O}^{\mathrm{NH}}$ NE of the most striking features of post-War biology has been the reanimation of Darwinism on a genotypic, instead of a phenotypic, basis. That such an attitude to evolutionary theory derives strong support from modern genetic and ecological work is undoubtedly the chief fact which emerged from the discussion on selection held on September 10 by Section D (Zoology) of the British Association at the recent Blackpool meeting. This occupied the first morning, and immediately followed Dr. J. S. Huxley's presidential address to the Section, which itself provided a comprehensive introduction to the subject. For his review of "Natural Selection and Evolutionary Progress" was a remarkable achievement, including almost everything that could and should be said in a general survey of selection.

In recent years experiment has largely replaced observation in the study of evolution. It is now plain that selection can operate only on genotypically controlled variability. Consequently, the effects of mutation, which is the initiation of a heritable variation, demand careful study. That these are nearly always disadvantageous need, however, cause us no surprise, for any organism must represent a system carefully balanced and adjusted to its environment ; so that any random change within it is immensely more likely to impair than to improve its efficiency. Yet occasional mutations have actually been observed which might be of advantage at least in special circumstances: like that mentioned by Dr. Huxley, in which a variety of tobacco failed to flower until the ratio of light to darkness was altered to correspond with what would prevail in a semi-tropical summer, when it proved superior to the normal form. But the relative viability of the genes may be most favourably compared in crowded cultures, when it can be studied as a deviation from expectation in Mendelian ratios. Dr. Timoféef-Ressovsky, who has elaborated this technique, pointed out that such tests also demon. strate that genes have different survival values in different degrees of crowding. For this work he has employed populations of Drosophila, and his method has provided an experimental basis for the study of selection in the laboratory.

Using the same genus, Dr. C. Gordon has now supplied proof of selective elimination in Nature. $\mathrm{He}$ finds that the number of autosomal recessives is very significantly in excess of the number of recessive sex-linked genes per length of chromatin -a discovery to be correlated with the fact that selection can operate on the former only when the genes in question are present in double dose, but on the latter, in every individual of the heterogametic sex in which they occur. Dr. Gordon has also demonstrated the reality of selection in Nature by releasing, and afterwards studying, a balanced population of Drosophila melanogaster. This consisted of normal and 'ebony' flies in a known ratio, set free in England, where the species is not indigenous. The latter is a dark mutant form, mono-factorial and recessive. It proved to be progressively eliminated in the open.

Selection, however, operates not merely to reject one character and conserve another: it may also alter the effects of the genes, but not the genes themselves. This view, the evolutionary implications of which have been developed only in recent years, follows naturally from the consideration that genetic factors interact with one another to produce the characters for which they are responsible. Thus mutations which are 